\title{
Nilai-nilai Moral dalam Sastra Klasik Folklor "Legenda Curug Orok" di Desa Cikandang, Kecamatan Cikajang Kabupaten Garut sebagai Upaya Pelestarian Nilai Budaya
}

\author{
${ }^{1}$ Iin Indriyani, ${ }^{2}$ Umi Kulsum \\ ${ }^{1,2}$ Institut Pendidikan Indonesia, Garut, Indonesia \\ Jalan Terusan Pahlawan No.32 Kec. Tarogong Kidul Kab. Garut Jawa Barat \\ 1iinindriyani@institutpendidikan.ac.id \\ ${ }^{2}$ umikulsum@institutpendidikan.ac.id
}

\begin{abstract}
Fairy tales are one of the cultural products originating from the Indonesian people. The existence of fairy tales is almost extinct today, eroded by the sophistication of communication technology. Even many young people today do not know that in the area where they live, there are stories stored. In fact, if we explore the contents of the messages in these fairy tales, there are a lot of moral values that can be used as guidelines for living life. Moral value is a value that regulates the way of life when we are in a society. The purpose of this study is to analyze the moral values in the folklore entitled "Legend of Curug Orok". This fairy tale comes from Cikandang Village, Cikajang District, Garut Regency. The research method used is descriptive analysis. The results of the researcher's analysis of the moral values contained in the folklore entitled "Legend of Curug Orok" are honesty, responsibility, independence, moral courage, and humility. The results of this study are expected to add insight to the wider community regarding the richness of Indonesian culture in the form of folk tales originating from areas in Garut Regency, as well as an effort to preserve it, so that the existence of this folklore does not become extinct.
\end{abstract}

Keywords: Fairy tales, Moral Values, Descriptive Analysis

\begin{abstract}
Abstrak
Dongeng merupakan salah satu hasil kebudayaan yang berasal dari masyarakat Indonesia. Keberadaan dongeng itu sendiri pada zaman sekarang hampir punah tergerus oleh kecanggihan teknologi komunikasi, bahkan banyak anak-anak muda sekarang yang tidak mengetahui bahwa di daerah tempat dia tinggal, ada cerita yang tersimpan. Padahal, kalau kita gali isi pesan yang ada di dalam dongeng-dongeng tersebut, banyak sekali nilai-nilai moral yang dapat dijadikan sebagai tuntunan untuk menjalani kehidupan. Nilai moral merupakan suatu nilai yang mengatur tata cara kehidupan ketika kita berada di dalam suatu lingkungan masyarakat. Tujuan dari penelitian ini yaitu untuk menganalisis nilai-nilai moral dalam cerita rakyat yang berjudul "Legenda Curug Orok". Dongeng ini berasal dari suatu Desa Cikandang, Kecamatan Cikajang, Kabupaten Garut. Metode penelitian yang digunakan yaitu deskriptif analisis. Hasil dari penganalisisan peneliti terhadap nilai-nilai moral yang berada di dalam cerita rakyat yang berjudul "Legenda Curug Orok" yaitu kejujuran, bertanggung jawab, kemandirian, keberanian moral, dan kerendahan hati. Hasil dari penelitian ini, diharapkan dapat menambah wawasan kepada masyarakat luas berkaitan dengan kekayaan budaya Indonesia berupa cerita-cerita rakyat yang berasal dari daerah-daerah yang berada di Kabupaten Garut, selain itu juga sebagai upaya untuk melestarikannya, sehingga keberadaan cerita rakyat ini tidak punah begitu saja .
\end{abstract}

\section{Kata kunci: Dongeng, Nilai Moral,Deskriptif Analisis}

\section{PENDAHULUAN}

Setiap daerah yang ada di Indonesia, biasanya memiliki suatu keunikan tersendiri, baik itu dari ciri khas makanan, pakaian, ataupun cerita-cerita mengenai asal-usul suatu daerah. Macam-macam keunikan yang ada di setiap daerah tersebut menjadikan Indonesia dikenal sebagai negara yang kaya akan budaya Cerita-cerita yang beredar di masyarakat Indonesia ada yang berjenis legenda, mitos, atau pun berjenis dongeng. Danandjaja [1] mengartikan folklor sebagai "Kebudayaan suatu kolektif yang tersebar dan diwariskan turun temurun secara tradisional dalam versi yang berbeda-beda dalam bentuk lisan maupun contoh yang disertai dengan gerak isyarat atau alat bantu pengingat".

Kekayaan budaya yang berasal dari setiap suku bangsa Indonesia, akan tetap terjaga kelestariannya seandainya kita mau tetap melestarikannya. Banyak cara dapat dilakukan untuk tetap menjaga kelestarian kekayaan budaya Indonesia tersebut, salah satunya yaitu dengan mengidentifikasi setiap 
cerita yang beredar di masyarakat luas. Legenda misalnya menjadi salah satu dari kekayaan budaya bangsa Indonesia, cerita-cerita mistis yang sering disebut ilmu kanuragan seperti leuweung larangan mau tidak mau menjadi hasanah budaya [2]. Dongeng adalah sebagai salah satu bentuk dari sastra klasik yang paling populer di masyarakat pada zaman dulu. Hampir di setiap daerah memiliki suatu cerita, tetapi sayangnya keberadaan cerita-cerita ini, semakin terancam karena kehadiran sastra modern. Hal tersebut tidak menutup kemungkinan untuk menjadikan dongeng sebagai warisan budaya yang terlupakan. Seperti yang dikatakan oleh Hutomo [3] "Fenomena kebudayaan lisan tradisional itu sebagai 'mutiara yang terlupakan' atau 'fosil hidup' yang keberadaannya diabaikan begitu saja”. Tujuan dari penelitian ini adalah untuk menganalisis nilai-nilai moral di dalam dongeng "Legenda Curug Orok" yang berasal dari Desa Cikandang Kecamatan Cikajang, Kabupaten Garut sebagai bentuk upaya di dalam melestarikan nilai-nilai budaya dalam cerita rakyat yang beredar di masyarakat luas, khususnya di Kabupaten Garut.

\section{KAJIAN PUSTAKA}

Sastra Lisan berdasarkan sejarahnya, bentuk sastra di Indonesia terbagi menjadi dua bagian, yaitu kesusastraan klasik (lama), dan kesusastraan baru (modern). Kesusastraan klasik (lama) adalah kesusastraan yang hidup dan berkembang pada masyarakat lama Indonesia dan menggunakan bahasa daerah, dan kesusastraan baru (modern), merupakan kesusastraan yang hidup dan berkembang dalam masyarakat Indonesia dengan menggunakan bahasa Indonesia. Menurut Ratna [4], "Secara historis sastra lama dimulai sejak berakhirnya masa prasejarah, sejak manusia mengenal kebudayaan, dengan hasil konkret berupa pepatah, dongeng, dan tradisi lisan yang lain, dan kemudian dilanjutkan dengan kebudayaan Hindu dan Islam hingga awal abad ke-20". Sastra modern dimulai sejak awal abad ke-20 yaitu setelah lahirnya angkatan Balai Pustaka.

Sastra klasik lebih dikenal dengan yang istilah sastra rakyat, karena sastra klasik itu merupakan hasil dari sekumpulan masyarakat yang diturunkan dari generasi ke generasi melalui bahasa lisan atau istilah lainnya disebut juga dengan folklor. Sutomo [5] membagi sastra lisan dari penampilannya terdiri atas dua jenis, yaitu: sastra lisan yang murni, dan sastra lisan yang setengah lisan. Sastra lisan murni adalah sastra lisan yang tidak membutuhkan alat-alat seni lain, seperti musik, sedangkan sastra lisan setengah lisan membutuhkan alat-alat kesenian lainnya.

Brunvand [3], membagi bahan-bahan tradisi lisan ke dalam tiga jenis pokok, di antaranya sebagai berikut : a. Tradisi Verbal, tradisi verbal mencakup lima kategori,yakni (1) ungkapan tradisional (termasuk pepatah, peribahasa, dan sebagainya); (2) nyanyian rakyat; (3) bahasa rakyat (misalnya dialek, julukan, sindiran, gelar-gelar, bahasa sandi, dan sebagainya; (4) teka-teki; (5) cerita rakyat (dongeng, mitos, legenda, sage, cerita jenaka, cerita cabul, dan lain sebagainya); b. Tradisi Setengah Verbal, tradisi setengah verbal meliputi tujuh kategori pokok, yakni: (1) drama rakyat (seperti ketoprak, ludrug, lenong, wayang orang, wayang kulit, dan lain sebagainya); (2) tarian rakyat (misalnya tarian serimpi, kuda lumping, serampang dua belas, dan lain sebagainya); (3) kepercayaan dan takhyul ( misalnya gugon tuhon); (4) upacara-upacara ritual (misalnya ulang tahun, kematian, perkawinan, sunatan, pertunangan, dan lain sebagainya); (5) permainan dan hiburan rakyat (misalnya macanan, gobag, sodor, sunda manda, dan lain sebgainya); (6) adat kebiasaan (misalnya gotong royong, batas usia khitanan, dan lain sebagainya); (7) pesta-pesta rakyat ( seperti sekaten wetonan, dan lain sebagainya); c. Tradisi Nonverbal, tradisi nonverbal mencakup dua tipologi dasar, yakni (1) tradisi yang berciri material ( misalnya mainan, makanan, minuman, peralatan dan senjata, alat musik, pakaian, dan perhiasan, obat-obatan, seni kerajinan tangan dan arsitektur rakyat); (2) tradisi nonmaterial ( misalnya irama musik gamelan Bali, Jawa, Sunda, dll ;menganggukkan kepala, menggelengkan kepala, dan lain sebagainya).

Nilai moral menurut Lillie (dalam Budiningsih, [4]) kata 'moral' berasal dari bahasa Latin, yaitu mores, yang berarti tata cara dalam kehidupan atau adat istiadat. Manusia adalah makhluk yang 
senantiasa melakukan berbagai aktivitas dalam kehidupan sehari-hari. Aktivitas tersebut tentunya mendorong manusia untuk berinteraksi dengan orang lain, seperti kodratnya manusia sebagai makhluk sosial yang membutuhkan bantuan dari orang lain. Ketika seorang manusia berinteraksi dengan sesamanya, tentu harus dapat mengontrol perilakunya, supaya keberadaannya tidak menimbulkan kerugian bagi orang lain. Tindakan moral tentunya sangat diperlukan dalam menjalankan kehidupan untuk menciptakan lingkungan yang kondusif. Seperti yang dikatakan oleh Budiningsih [6] “ Tindakan moral yaitu kemampuan untuk melakukan keputusan dan perasaan moral ke dalam perilaku-perilaku nyata".

Karya sastra adalah hasil cipta manusia, dongeng adalah salah satu bentuk dari karya sastra itu sendiri. Tujuan dari penciptaan dongeng, bukan hanya semata-mata untuk menuangkan isi dari pikiran si pengarangnya, tetapi ada tujuan lain yang ingin dicapai dari hasil mencipta dongeng tersebut, yaitu penyampaian pesan-pesan dari pengarang kepada pembaca atau penyimaknya. Pengarang menginginkan pembaca atau penyimak memahami pesan-pesan moral yang ada di dalam isi cerita dongeng. Nurgiyantoro [7] "Moral adalah sesuatu yang disampaikan pengarang terhadap pembaca melalui karya-karyanya. Diperkuat dengan pendapat lain mengenai pesan moral, Magnis dan Suseno [8] "Pesan moral adalah pesan yang berisikan ajaran-ajaran, wejangan-wejangan lisan maupun tulisan, tentang bagaimana manusia itu harus hidup dan bertindak, agar ia menjadi manusia yang baik.

Magnis dan Suseno [8] membagi pesan moral ke dalam beberapa jenis, diantaranya adalah sebagai berikut: a. Kejujuran, sikap jujur berarti apa yang diungkapkan sesuai dengan fakta atau sesuai dengan kenyataan. Sikap jujur dari seseorang dapat menumbuhkan kepercayaan orang lain kepada seseorang. Sikap jujur adalah sikap yang tidak menentang suara hati atau terhadap suatu keyakinan; b. Menjadi Diri Sendiri, sikap menjadi diri sendiri yaitu tidak mudah terpengaruh oleh lingkungan yang bisa merugikan diri sendiri, sikap menghayati dan menunjukkan diri sesuai dengan keasliannya, karakter yang kuat dan matang sesuai dengan kebenaran. Sikap menjadi diri sendiri merupakan keyakinan yang kuat tanpa terpengaruh lingkungan dan perkembangan zaman, artinya manusia mempunyai pendirian yang kuat terhadap suatu kebenaran; c. Bertanggung Jawab, sikap bertanggung jawab berarti kesediaan dalam melakukan apa yang harus dilakukan dengan sebaik mungkin. Sikap tanggung jawab dapat tercermin dalam pelaksanaannya tanpa ada alasan rasa malas, takut atau malu untuk melakukan tanggung jawab yang dilakukan. Sikap tanggung jawab merupakan hal yang sangat penting dalam kehidupan seseorang, karena sikap tanggung jawab akan menunjukkan seberapa besar seseorang berani untuk melakukan apapun demi tanggung jawabnya; d. Kemandirian, sikap kemandirian adalah kekuatan batin untuk mengambil sikap moral sendiri dan bertindak sesuai norma, tanpa perlu selalu bergantung pada bantuan orang lain. Kemandirian dapat melatih manusia untuk dapat hidup dalam lingkungan dan kondisi apapun.; e. Keberanian Moral, sikap keberanian moral adalah kesetiaan terhadap suara hati, keberanian untuk mempertahankan sikap yang diyakini sebagai suatu kewajiban tanpa melanggar nilainilai moral walau harus mengambil resiko konflik. Sikap keberanian moral memiliki keutamaan, yaitu tidak mudah mundur dalam melakukan tanggung jawab tanpa melanggar norma kehidupan; $\mathrm{f}$. Kerendahan Hati, sikap kerendahan hati merupakan suatu sikap yang tidak berlebihan atau menyombongkan diri, melainkan melihat diri sendiri sesuai dengan kenyataannya, tetapi bukan berarti merendahkan diri. Sikap kerendahan hati bukan berarti sikap mengalah, orang yang tidak berani, dan tidak mampu membela suatu pendirian, akan tetapi sikap kerendahan hati memberikan pemahaman bahwa sebagai manusia mempunyai kekuatan terbatas, akal yang terbatas, setiap usaha yang dilakukan bisa gagal dan tidak selalu tercapai dengan apa yang diinginkan. Manusia seharusnya memiliki sifat rendah hati, tidak sombong dengan segala pencapaian yang telah dimilikinya; g. Kritis, sikap kritis yaitu suatu tindakan untuk dapat mengoreksi, memberikan saran baik terhadap segala kekuatan, kekuasaan dan wewenang yang dapat merugikan kehidupan individu maupun masyarakat. Sikap kritis pada dasarnya memberikan suatu saran yang bermanfaat pada seseorang maupun untuk diri kita sendiri agar kedepannya menjadi lebih baik dalam bertindak di kehidupan sehari-hari. Seseorang diharapkan 
memiliki sikap kritik terhadap segala hal yang, terutama kepada yang melanggar norma-norma kehidupan. Tujuannya supaya dapat saling mengingatkan satu sama lain. Nilai moral dan karakter bangsa perlu ditanamkan kepada generasi milenial saat ini melalui hasanah budaya lokal atau kearifan nilai-nilai lokal [9].

\section{METODE PENELITIAN}

Metode penelitian yang digunakan dalam penelitian ini yaitu menggunakan metode deskriptif analisis. Tujuan utama dari penggunaan metode ini, adalah untuk menganalisis keadaan suatu objek. Objek tersebut dianalisis, kemudian data-data yang sudah terkumpul dari hasil penganalisisan tersebut, peneliti identifikasi sesuai tujuan penganalisisan yaitu menganalisis nilai-nilai moral yang terkandung dalam cerita rakyat "Legenda Curug Orok". Instrumen penelitian yang digunakan untuk mendukung penelitian ini adalah kisi-kisi pedoman observasi dan kisi-kisi pedoman wawancara. Peneliti melakukan observasi ke tempat objek cerita, lalu melakukan wawancara dengan salah satu tokoh masyarakat yang mengetahui keberadaan cerita. Informan yang peneliti wawancara, merupakan orang yang menjabat sebagai lurah di Desa Cikandang, Kecamatan Cikajang Kabupaten Garut.

Teknik yang digunakan untuk pengumpulan data yaitu teknik observasi dan wawancara. Langkah pertama yang dilakukan peneliti dalam pengumpulan data yaitu melakukan observasi ke objek penelitian. Teknik ini dilakukan dengan cara melakukan penelusuran dan penelitian terhadap keberadaan cerita di masyarakat setempat. Langkah kedua, yaitu mencari keberadaan informan yang mengetahui cerita berkaitan dengan seluk beluk cerita yang ada dalam masyarakat setempat, konteks penuturan cerita, serta proses penciptaan cerita yang dianalisis dalam masyarakat setempat. Langkah ketiga, informasi dari informan, peneliti dokumentasikan melalui wawancara tertulis dan rekaman. Langkah keempat, melakukan proses alih bahasa hasil wawancara, baik itu tertulis maupun rekaman dari bahasa asli (Sunda) ke dalam bahasa Indonesia tanpa mengubah atau menghilangkan makna aslinya. Langkah kelima, melakukan penganalisisan dan pengolahan terhadap dongeng dengan menganalisis nilai-nilai moral yang terkandung di dalamnya.

\section{HASIL DAN PEMBAHASAN}

\section{Deskripsi Dongeng}

\section{"Legenda Curug Orok"}

Diceritakan ada sebuah keluarga, namanya Mang Ahmad, dan istrinya Bi Suharti, keluarga ini hidup rukun walaupun sederhana. Untuk memenuhi kehidupan sehari-harinya, mereka mengandalkan dari hasil pertanian yang mereka tanam sendiri. Bertani di sebuah kebun yang subur, karena dikelilingi oleh air terjun yang begitu indahnya.

Di kebun tersebut Mang Amad menanam berbagai macam sayuran. Mereka sangat menyukai tinggal di tempat ini, karena selain tanahnya subur, juga aliran airnya yang tidak berhenti meskipun kemarau, sehingga mampu mengairi lahan pertanian Mang Ahmad.

Pada suatu hari, Mang Amad pergi mengambil air ke bawah, tempat di mana air terjun itu berada. Ketika sampai di bawah, dia sangat terkejut sekali, karena mendengar suara tangisan bayi, lalu suara tangisan tersebut ia didekati. Ketika sampai, Mang Amad terkejut karena suara tangisan itu ternyata berasal seorang bayi laki-laki yang sedang menangis di atas batu. Walaupun kaget, Mang Ahmad membawa bayi tersebut ke rumah dan diserahkan kepada istrinya. Katanya bayi yang dia temukan itu, sepertinya sengaja dibuang oleh orang tuanya.

Selanjutnya bayi tersebut dipelihara oleh Mang Amad dan Bi Suharti sebagaimana mereka anggap anaknya sendiri. Mereka sangat menyayangi anak tersebut, kebetulan keduanya menikah sudah lama dan belum dikaruniai anak. Mereka merasa sangat beruntung dan bersyukur sekali mendapatkan bayi tersebut.

Ketika menginjak umur tiga tahun, anak tersebut sakit parah, yang akhirnya nyawanya tidak tertolong lagi. Mang Amad dan Bi Suharti sangat sedih, oleh Mang Amad jasad anak tersebut dikubur 
di bawah air terjun dimana anak tersebut ditemukan dulu untuk pertama kalinya. Maka, berdasarkan dari cerita tersebut masyarakat memberikan nama pada tempat itu dengan nama Curug Orok. Tempat tersebut sekarang menjadi sebuah objek pariwisata yang ramai dikunjungi baik itu oleh masyarakat domestik maupun oleh tamu mancanegara.

\section{Analisis Nilai-nilai Moral dalam "Legenda Curug Orok" di Desa Cikandang, Kecamatan Cikajang, Kabupaten Garut}

Nilai-nilai moral yang ada di dalam cerita "Legenda Curug Orok", meliputi beberapa hal, di antaranya adalah sebagai berikut ini.

a. Kejujuran

Di dalam cerita "Legenda Curug Orok", terdapat nilai-nilai 'kejujuran'. Hal tersebut dibuktikan dengan adanya penggalan cerita pada paragraf ketiga, di mana tokoh utama Mang Ahmad menceritakan kejadian yang sebenarnya kepada istrinya yang bernama Bi Suharti, tentang penemuan seorang anak di tempat air terjun. Apa yang dilakukan oleh mang Ahmad tersebut, tujuannya untuk menghindari kecurigaan dari istrinya, sehingga tidak menimbulkan kesalahpahaman yang nantinya berakibat kepada ketidakharmonisan keadaan rumah tangganya.

b. Bertanggung Jawab

Di dalam cerita "Legenda Curug Orok", terdapat nilai moral 'bertanggung jawab'. Hal tersebut dibuktikan dengan adanya penggalan cerita yang menceritakan bahwa Mang Ahmad dan istrinya, menjadikan bayi yang ditemukan di dekat air terjun tersebut menjadi anak angkatnya, mereka berdua begitu menyayangi bayi tersebut, walau akhirnya bayi tersebut meninggal dunia.

c. Kemandirian

Di dalam cerita "Legenda Curug Orok", terdapat nilai moral 'kemandirian'. Hal tersebut dapat dibuktikan dengan adanya penggalan cerita yang menjelaskan bahwa, untuk memenuhi kebutuhan hidup sehari-harinya Mang Ahmad bercocok tanam di kebun dekat dengan aliran sungai dari air terjun.

d. Keberanian Moral

Di dalam cerita "Legenda Curug Orok", terdapat nilai moral 'keberanian moral'. Hal tersebut dapat dibuktikan dengan adanya penggalan cerita yang menjelaskan bahwa, ketika Mang Ahmad menemukan seorang bayi di dekat air terjun, dia memiliki keberanian moral untuk menyelamatkan dan membawa bayi yang ditemukannya ke rumah, dia merasa kasihan kepada bayi tersebut karena telah ditinggalkan oleh orang tua yang telah membuangnya, lalu mengurusnya dengan sepenuh hati bersama istrinya $\mathrm{Bi}$ Suharti.

\section{e. Kerendahan Hati}

Di dalam cerita "Legenda Curug Orok", terdapat nilai moral 'kerendahan hati'. hal tersebut dapat dibuktikan dengan adanya penggalan cerita yang menjelaskan bahwa, Mang Ahmad dan Bi Suharti merasa bersyukur, setelah sekian lama mereka menikah dan tidak memiliki anak, akhirnya mereka diberikan kesempatan oleh Allah Swt. untuk mengurus seorang bayi dengan penuh kasih sayang. Rasa syukur tersebut menunjukkan kerendahan hati keduanya kepada Allah Swt. atas segala karunia-Nya.

\section{KESIMPULAN DAN SARAN}

Berdasarkan analisis nilai-nilai moral terhadap cerita rakyat yang berjudul "Legenda Curug Orok" yang berasal dari Desa Cikandang, Kecamatan Cikajang, Kabupaten Garut, maka dapat disimpulkan bahwa nilai-nilai moral yang terdapat di dalamnya adalah: kejujuran, bertanggung jawab, kemandirian, keberanian moral, dan kerendahan hati. Nilai-nilai moral tersebut membuktikan bahwa di dalam cerita rakyat selalu terkandung nilai-nilai moral atau kemanusiaan yang dapat dijadikan sebagai bahan renungan untuk dijadikan cermin dalam menjalani kehidupan. 


\section{DAFTAR PUSTAKA}

[1] Danandjaja, J. (1991). Folklor Indonesia: Ilmu Gosip, Dongeng, dan Lain-lain. Jakarta: Grafiti Press.

[2] Triani, W \& Tetep, (2019). Eksistensi Ilmu Kanuragan Rajah Pakuwon di Era Globalisasi. Civicos (Civics and Social Studides Journal). Volume-3 No 2 Desember 2019. ISSN-2655$\underline{7304}$ dan e-ISSN : 2655-896. DOI : https://doi.org/10.31980/2655-7304.v3i2. https://journal.institutpendidikan.ac.id/index.php/journalcss/issue/view/49

[3] Hutomo, S. (1991). Mutiara yang terlupakan: Pengantar Studi Sastra Lisan. Surabaya: HISKI Jawa Timur.

[4] Ratna, K.N. (2004). Teori, Metode, dan Teknik Penelitian Sastra.2004. Pustaka Pelajar: Yogyakarta.

[5] Taum, Y.Y. (2011). Studi Sastra Lisan: Sejarah, Teori, Metode dan Pendekatan Disertai Contoh Penerapannya. Lamalera: Yogyakarta.

[6] Budiningsih, C.A. (2004). Pembelajaran Moral (Berpijak Pada Karakteristik Siswa dan Budayanya). Jakarta: PT Rineka Cipta.

[7] Nurgiyantoro, B. (2012). Teori Pengkajian Fiksi. Jakarta: Gadjah Mada University Press.

[8] Magnis, F. dan Suseno. (1987). Etika Dasar, Masalah-masalah Pokok Filsafat Moral. Yogyakarta: Kanisius.

[9] Tetep \& Eldi, M. (2019). Nation Character Building for Millennial Generation Based on Local Wisdom of Saminism. Advances in Social Science, Education and Humanities Research. Vol 458, 4 August 2020. 2352-5398 / 978-94-6252-999-1. DOI: https://doi.org/10.2991/assehr.k.200803.025. https://www.atlantis press.com/proceedings/icssgt-19/125942802 